\title{
Hoarseness After Shoulder Surgery in Beach-chair Position
}

\author{
Seung-Min Youn \\ Myongji Hospital \\ Sung-Min Rhee \\ Kyung Hee University Medical Center \\ Hwan Jin Kim \\ Kyung Hee University Medical Center \\ Hyun Woo Lee \\ Kyung Hee University Medical Center \\ Seong Cheol Moon \\ Kyung Hee University Medical Center \\ Soonghwan Cho \\ Myongji Hospital \\ Yong Girl Rhee ( $\nabla$ shouldermee@hanmail.net ) \\ Myongji Hospital
}

\section{Research Article}

Keywords: Vocal cord palsy, Recurrent laryngeal nerve injury, Beach-chair position, Shoulder arthroscopy, Operative time, Surgical duration, Anesthetic duration, Cervical spine curvature

Posted Date: March 15th, 2021

DOI: https://doi.org/10.21203/rs.3.rs-290036/v1

License: (c) (i) This work is licensed under a Creative Commons Attribution 4.0 International License. Read Full License 


\section{Abstract}

Background Isolated vocal cord palsy resulting hoarseness after shoulder surgery in beach-chair position had not been reported in literature to date. The purpose of this study was to review its incidence in our patient cohort, and identify any risk factors that may predispose the patient to the injury.

Methods There were 10215 operative shoulder cases from January 2010 to December 2017. Inclusion criteria was any post-operative patients, whose operation was performed under general anesthesia in beach-chair position, who had the related symptoms, but the diagnoses had to be confirmed by otorhinolaryngologists with laryngoscopy studies. The affected patients' clinical notes were retrospectively reviewed with the particular interest in the operative times, and the peri-operative cervical spine radiographs. The degree of cervical spine lordosis was assessed using a method described in literature, in which 'absolute rotation angle' (ARA) was measured.

Results There were 8 reported cases of vocal cord injury in total (0.08\%). Four were male patients and four were arthroscopic cases. The mean age was $59.4 \pm 11.9$ years old. No particular difficulties with positioning or intubation were documented. The average duration of anesthetic times was 141 minutes. On peri-operative cervical spine radiographs, the average lordosis was $8.2^{\circ}\left(1.5^{\circ}\right.$ kyphosis - $21^{\circ}$ lordosis $)$, and except for one patient, all had 'non-lordotic' type curvatures. All but one patient had recovered fully with observation and expectant management, with the average recovery time being 19 weeks (range: 2 weeks to 1 year). Only patient who had not recovered during our 2-year follow-up period, had a 'sigmoidal' type cervical spine and was also managed with observation only.

Conclusions The incidence of vocal cord injury with beach-chair positioning at our institution was low at $0.08 \%$. The possible risk factors include long duration of the procedure and 'non-lordotic' cervical spine, as demonstrated by the trend in our study. Although rare, vocal cord injury has varying duration of recovery time, in the worst-case scenario being permanent, therefore it needs to be avoided by taking utmost care during positioning of the patient in beach-chair.

Level of Evidence Level IV, case series

\section{Introduction}

There has been increasing number of arthroscopic shoulder procedures being done around the world over the last decade. The surgeons' preference for utilizing beach-chair position for such procedures have increased also. The beach-chair position for shoulder arthroscopy has a few advantages over the lateral decubitus position [1, 2]. The upright position of the shoulder can provide the surgeon with more intuitive visualization of the anatomical structures and locations, and to help further with the visualization, rotation and traction of the joint can be achieved easily with or without the help of an arm holding device [2]. Furthermore, conversion to an open shoulder procedure can be done easily and rapidly in the same setting if required $[2,3]$.

The most well-known complication relates to the lowering of blood circulation to brain, however there have also been reports of other complications peripherally which include injuries to cornea, great auricular nerve and sciatic nerve to name a few [2, 4-6]. One major concern while sitting the patient up on beach-chair position is the rapidly altering position of the cervical spine. This rapidly changing position and mal-positioning of the patient's head and neck for a period of time or even temporarily, could result in neurological complications- injury to the hypoglossal nerve and also in combination with the recurrent laryngeal nerve (RLN) and other cranial nerves after beach-chair position have been reported in the past [7-9].

The RLN is certainly one of the structures vulnerable to injury during beach-chair positioning as the patient's larynx could be stretched while flexing and rotating the neck, along with the endotracheal tube (ETT) and its cuff in inflated state which could also indirectly pressure the nerve at the same time [10-12]. Either compressional or traction injury, or both, to the RLN can result in vocal cord palsy which may manifest as hoarseness in varying degree of severity [13]. Throat discomfort and difficulties with swallowing may also be present. In the worst-case scenario, dysfunction with swallowing may result in aspiration. The recovery of the RLN palsy could be unpredictable and its damaged state could potentially be permanent [14-16], therefore although its occurrence is rare, it needs to be avoided by taking extra care while positioning and manipulating the patient's neck.

Although there are some reports on the RLN palsy after anterior neck procedures including of the cervical spine and thyroid among many others [15-19], the nerve palsy in isolation from shoulder surgery and its beach-chair position has not been reported to date. The aim of the study was to review all the cases of diagnosed vocal cord injuries post shoulder procedures done in beach-chair position at our institution, and determine any factors that might have contributed to the complication including the curvatures of patients' cervical spines. We hypothesized that the longer duration of procedure and cervical kyphosis may increase the risk of the RLN palsy.

\section{Materials And Methods}

The study protocol is performed in accordance with the relevant guidelines.

\section{Patient Selection}


During the 8-year period between January 2010 to December 2017, there were 10215 operative shoulder cases at our institution, performed by a single surgeon. The Institutional Review Board at our institute approved the study protocol. The inclusion criteria consisted of patients who underwent any shoulder surgery in beach-chair position, which were performed under general anesthesia, and of those who had the vocal cord palsy diagnosed eventually with a fiber-optic laryngoscopy study after complaining of the symptoms post-operatively. The laryngoscopy should have clearly shown paralysis or less abduction/adduction movement of the vocal cord(s), usually resulting in the asymmetrical appearance during phonation and inhalation (Fig. 1). The final diagnosis of vocal cord injury with laryngoscopy study was made by the senior otorhinolaryngologists at this institution, with 10 years or more experience in their field of subspecialty. Patients who had received only regional anesthesia, were excluded. The senior author had not performed any surgery with the patient in lateral decubitus position during this period of study.

\section{Data Collection}

Once included in the study, the patients' demographic information including body mass index (BMI) and co-morbidities were recorded (Table 1). Medical documentation including their operation notes and clinic notes were reviewed, in particular to see if there were any unusual or difficult parts during their surgical preparation, procedure itself or recovery. The clinical photographs from laryngoscopy studies were reviewed. The peri-operative plain radiographs of the patients' cervical spines were reviewed and classified according to their curvatures in the lateral plane films. The subtypes of the curvature were classified by two orthopaedic fellows according to the descriptions and modifications used in literature, which were either described as 'Iordotic', 'straight', 'globally kyphotic', 'sigmoidal' or 'reverse sigmoidal' [20, 21]. The degree of lordosis angle was obtained by the method of measuring absolute rotation angle (ARA) from cervical (C) vertebral bodies through 2 to 7 on plain lateral radiographs. The ARA was measured from the angle created by the two longitudinal lines aligned to the posterior margins of $\mathrm{C} 2$ and $\mathrm{C} 7$ vertebral bodies [21].

Table 1

Demographic information of the 8 vocal cord injury patients

\begin{tabular}{|ll|}
\hline Demographics & $\mathbf{n}=\mathbf{8}$ \\
\hline Age (average \pm SD*) & $59.4 \pm 11.9$ \\
\hline Gender (male $:$ female) & $4: 4$ \\
\hline BMI (average \pm SD*) & $24.5 \pm 1.9$ \\
\hline Laterality of vocal cord injury (right : left) & $5: 3$ \\
\hline Laterality of injury and operated side (same : opposite) & $5: 3$ \\
\hline Procedure type (open : arthroscopic) & $4: 4$ \\
\hline Co-morbidities & Hypertension $(n=2)$ \\
\hline & Thyroid mass $(n=1)$ \\
\hline Concomitant injuries & Rheumatoid arthritis $(n=1)$ \\
\hline & Arytenoid cartilage dislocation $(n=1)$ \\
\hline * Standard deviation & Hypoglossal nerve injury $(n=1)$ \\
\hline
\end{tabular}

\section{Anesthetic Procedure}

The anesthetic records were reviewed to see if any difficulties were encountered with the airway maintenance especially during the anesthetic induction and intubation, and their ETT sizes were noted: 4 patients had size 7.5 ETTs and the rest had size 7. The ETTs were inflated to the pressure of $20-30 \mathrm{cmH}_{2} \mathrm{O}$ in average. There were no other atypical agents being administered during the induction of the included patients and no other specialized maneuvers were needed in order to achieve intubation and secure the airway. The durations of total anesthetic time, which included the operative time, for all cases were reviewed.

\section{Beach-Chair Positioning}

After patient is given general anesthesia on the operating table while lying supine, the ETT is inserted and fixed around the jaws and face appropriately. Eyelids are made sure to be kept shut and gently taped. A standard head rest (Allen Amatech, Allen Medical Systems, Acton, MA, USA) for the beach-chair table is used. The head is placed into the head rest and temporarily held with steady manual control of the head/neck by the surgeon while the ETT is temporarily disconnected by the anesthetist for sitting up of the upper body. With the wedged pillow under the lower limbs and the buttock being placed right up against the folding part of the bed to prevent slipping, the upper body is raised to approximately 50 to 70 degree position while the surgeon is holding and keeping the head neutral during the elevation. The airway is reconnected once the appropriate angle of sitting up is achieved. Once the head and neck are checked to be sitting in a neutral position with or without the manual control i.e. without 
lateral tilting, rotation or hyper-flexion or -extension, a white foamed strap is placed across the forehead as well as around the jaws from ear-to-ear, and another Velcro strap is placed firmly over the foam on the forehead. The final check is done to make sure the head and neck are firmly securedif required, and extra bandage could be used to wrap around the forehead and jaws/chin for reinforcement, however one must make sure that this is not too tight around the neck or face (Fig. 2). The contralateral arm is placed onto the padded arm board attached to the table, and the rest of the peripheries are made to be padded well also, before commencing our sterile draping.

\section{Results}

Of the 10215 operative shoulder cases, eight cases $(0.08 \%)$ were shown to be diagnosed with vocal cord palsy as a post-operative complication. Of these, three patients had arthroscopic rotator cuff repairs, another patient had an arthroscopic Bankart repair, and the rest had open procedures namely for a subscapularis repair, a primary total shoulder arthroplasty, a primary reversed total shoulder arthroplasty, and a revision of reversed total shoulder arthroplasty. Therefore, there were 4 arthroscopic and 4 open cases (Tables 1, 2). There were 4 men and 4 women with the mean age of $59.4 \pm 11.9$ years old. The mean body mass index was $24.5 \pm 1.9 \mathrm{~kg} / \mathrm{m}^{2}$. One of the patients was reported to have a thyroid mass. Two patient had hypertension and another patient had rheumatoid arthritis as co-morbidities. Four patients' vocal cord palsies were on the right side- five patients had the palsies on the same side as the operative side, while the rest had it on the opposite side. Two patients had concomitant injuriesone had arytenoid cartilage dislocation (case 5, Table 2), and the other had hypoglossal nerve injury (case 6, Table 2). All patients complained of hoarseness but three of them also complained of discomfort, dyspnea, and swallowing difficulties. Protruding tongue was described by the patient with the concomitant hypoglossal nerve injury.

Table 2

Patient demographics, duration of the operative/anesthetic times, treatment, and cervical radiographic findings.

\begin{tabular}{|c|c|c|c|c|c|c|c|c|c|c|}
\hline $\begin{array}{l}\text { Case } \\
\text { number }\end{array}$ & $\begin{array}{l}\text { Age at } \\
\text { time of } \\
\text { operation } \\
\text { (years) }\end{array}$ & Gender & Operation & $\begin{array}{l}\text { Operative } \\
\text { side }\end{array}$ & $\begin{array}{l}\text { Vocal } \\
\text { cord } \\
\text { injury } \\
\text { side }\end{array}$ & $\begin{array}{l}\text { Duration } \\
\text { of } \\
\text { anesthetic } \\
\text { time } \\
\text { (minutes) }\end{array}$ & Treatment & $\begin{array}{l}\text { Time to } \\
\text { recovery } \\
\text { (weeks) }\end{array}$ & $\begin{array}{l}\text { Co- } \\
\text { morbidities }\end{array}$ & $\begin{array}{l}\text { Cervical } \\
\text { curvature } \\
\text { type }\end{array}$ \\
\hline 1 & 59 & Male & $\begin{array}{l}\text { Arthroscopic } \\
\text { rotator cuff } \\
\text { repair }\end{array}$ & Left & Right & 155 & $\begin{array}{l}\text { Observation, } \\
\text { expectant } \\
\text { management* }\end{array}$ & 8 & & Straight \\
\hline 2 & 41 & Female & $\begin{array}{l}\text { Arthroscopic } \\
\text { Bankart repair }\end{array}$ & Right & Right & 115 & $\begin{array}{l}\text { Observation, } \\
\text { expectant } \\
\text { management }\end{array}$ & 3 & & $\begin{array}{l}\text { Globally } \\
\text { kyphotic }\end{array}$ \\
\hline 3 & 81 & Female & $\begin{array}{l}\text { Revision of } \\
\text { reversed total } \\
\text { shoulder } \\
\text { arthroplasty }\end{array}$ & Left & Left & 285 & $\begin{array}{l}\text { Observation, } \\
\text { expectant } \\
\text { management }\end{array}$ & 52 & Hypertension & Straight \\
\hline 4 & 67 & Female & $\begin{array}{l}\text { Arthroscopic } \\
\text { rotator cuff } \\
\text { repair }\end{array}$ & Right & Left & 100 & $\begin{array}{l}\text { Observation, } \\
\text { expectant } \\
\text { management }\end{array}$ & 2 & & Sigmoidal \\
\hline 5 & 65 & Male & $\begin{array}{l}\text { Reversed } \\
\text { total shoulder } \\
\text { arthroplasty }\end{array}$ & Right & Right & 150 & $\begin{array}{l}\text { Closed } \\
\text { reduction of } \\
\text { dislocated } \\
\text { arytenoid } \\
\text { cartilage }\end{array}$ & 8 & Hypertension & $\begin{array}{l}\text { Reverse } \\
\text { sigmoidal }\end{array}$ \\
\hline 6 & 54 & Male & $\begin{array}{l}\text { Total } \\
\text { shoulder } \\
\text { arthroplasty }\end{array}$ & Left & Left & 145 & $\begin{array}{l}\text { Observation, } \\
\text { expectant } \\
\text { management }\end{array}$ & 52 & & Lordotic \\
\hline 7 & 53 & Female & $\begin{array}{l}\text { Arthroscopic } \\
\text { rotator cuff } \\
\text { repair }\end{array}$ & Right & Right & 80 & $\begin{array}{l}\text { Observation, } \\
\text { expectant } \\
\text { management }\end{array}$ & 8 & $\begin{array}{l}\text { Rheumatoid } \\
\text { arthritis }\end{array}$ & Straight \\
\hline 8 & 55 & Male & $\begin{array}{l}\text { Open } \\
\text { subscapularis } \\
\text { repair }\end{array}$ & Right & Left & 100 & $\begin{array}{l}\text { Observation, } \\
\text { expectant } \\
\text { management }\end{array}$ & nil & & Sigmoidal \\
\hline
\end{tabular}

\section{The Duration of Total Anesthetic Time}

The mean duration of total anesthetic time was 141 minutes (standard deviation of \pm 64.1 ). Two cases were recorded as having duration of more than 2 hours (case 1 and 3, Table 2)- one was an arthroscopic rotator cuff repair that took 155 minutes and apart from being a large tear, no other difficulties with induction or intubation were noted; the other case was a revision of reversed total shoulder arthroplasty that took 285 minutes, being 
performed in a single stage, requiring complete removal of the original implant and its cementation followed by bone grafting procedure to address the significant osteolysis, all of which can explain its excessive duration of the anesthetic as well as the operative time.

\section{Peri-operative Radiographic Assessment of Cervical Spine Curvature}

The cervical spine radiographs reviewed for the affected patients were either performed pre-operatively close to the time of surgery or postoperatively after the diagnoses of the vocal cord injuries as part of the investigation. The pre-operative cervical spine radiographs were done occasionally at clinic when cervical pathology was being ruled out for the symptoms. On review of these plain radiographs, none had a cervical rib. The average angle of the curvature was $8.2^{\circ}$ lordosis (range: $1.5^{\circ}$ kyphosis $-21^{\circ}$ lordosis). Except for one patient, all had non-lordotic subtype cervical spines (Table 3)- three had 'straight' subtypes, one was 'globally kyphotic', two had 'sigmoidal', and one had 'reverse sigmoidal' subtype (Figs. 3, 4).

Table 3

Plain cervical lateral radiographic findings including types of spinal curvature

\begin{tabular}{|ll|}
\hline Radiographic Findings & $\mathbf{n = 8}$ \\
\hline Cervical rib & 0 \\
\hline Cervical spine curvature types: & \\
\hline Lordotic & 1 \\
\hline Straight & 3 \\
\hline Globally kyphotic & 1 \\
\hline Sigmoidal & 2 \\
\hline Reverse sigmoidal & 1 \\
\hline Cervical lordosis angle (range) & $8.2^{\circ}\left(1.5^{\circ}\right.$ kyphosis $-21^{\circ}$ lordosis $)$ \\
\hline
\end{tabular}

\section{Recovery after Vocal Cord Palsy}

All patients except one did recover fully with expectant management that included administration of oral prednisolone for a week. One patient required closed reduction of the dislocated arytenoid cartilage under another anesthetic, but later achieved full recovery. For the recovered patients, the average time to full recovery was 19 weeks (range: 2 weeks - one year). Two patients had the symptoms lasting for a month or less, while the other five had the symptoms for two months or more.

One patient had not recovered from the vocal cord palsy during his follow-up for the 2-year period. This was an otherwise fit and well 55-year-old male, who had an open subscapularis tear repair- his cervical spine radiograph revealed 'sigmoidal' subtype of curvature with the lordosis angle of $5.5^{\circ}$. There was no particular mention of difficulties with the induction of anesthesia or intubation in the documented notes. The ETT size was 7.5. The total anesthetic time for this patient was recorded as 100 minutes. The BMI was recorded as $26.0 \mathrm{~kg} / \mathrm{m}^{2}$.

\section{Discussion}

The incidence of vocal cord palsy or the RLN palsy was $0.08 \%$ in our data, however, for those affected by it had issues with the symptoms lasting for a varying duration, and there was one patient who had never recovered from it and one other who required another anesthetic to undergo closed reduction of the dislocated arytenoid cartilage as the main treatment.

There have been reports of various neurological and non-neurological complications related to beach-chair or sitting-up position required during shoulder and neurosurgery [2, 4-9, 22, 23]. Mullins et al. [22] and Rhee et al. [9] both reported the rare incidence of hypoglossal nerve palsy during beach-chair position, and others have reported combination of the RLN and hypoglossal nerve palsies [7], as well as the other cranial nerve palsies [8]. The isolated RLN palsy has been reported in anterior cervical spine and thyroid procedures as well as the others that require anterior neck dissection [14-17, 19], however, it has not been reported or investigated for beach-chair position during shoulder surgery to date. The RLN palsies related to ETT and intubation have been described by the anesthesiologists [11, 18, 19, 24, 25]- Kikura et al. [24] reported the risk of the nerve palsy was 3 times higher with the patients aged 50 years or older and there was two-fold increase in the risk with the duration of operative time being more than 3 hours. The risk increased to fifteen-fold if the duration was more than 6 hours. Type 2 diabetes and hypertension as co-morbidities also increased the risk [24]. In our patients with confirmed vocal cord palsies, two patients had hypertension as co-morbidities, and there were no patients with diabetes. All but one patient was over the ages of 50 years, which could be seen as a possible risk factor to the vocal cord palsy. One of the patients with hypertension was 81 years of age who underwent revision shoulder arthroplasty surgery that took more than 180 minutes, thus having a significantly increased risk of the vocal cord palsy. 
The RLN is a branch of the vagus nerve (CNX) that innervates all muscles of larynx except for cricothyroid muscles. It innervates posterior cricoarytenoid muscles which are the only muscles that can open the vocal cords [13]. Its anatomical course is different on each side of the mediastinum and neck, and there can be variation in its course especially of the right side $[13,14,16,26]$. This variation, along with the close proximity of the nerve to the larynx, means that it can be vulnerable to injury during surgical neck dissection or manipulation of the cervical spine. A porcine study also showed that the right RLN was less stiff and was subjected to higher tension during manipulation of thyroid [16], thus had higher risk of injury than the left. Ligament of Berry is thought to be the structure holding the thyroid to the laryngotracheal complex and the distal $2 \mathrm{~cm}$ of the RLN is in close proximity to the ligament, where it is vulnerable to injure $[13,26]$. According to another anatomical and clinical study, the RLN never penetrates the ligament of Berry but is located dorsolateral to it, still running very close to this structure [16, 26]. All these facts about anatomy tell us that pressure or manipulation around the laryngotracheal structures can predispose the RLN to stretching and injury. In our study, we had equal numbers of the affected sides but due to the injury's rare incidence in our cohort, it is difficult to comment further on our findings.

Others have suggested that the external pressure or manipulation may not be the only factors behind the RLN injury, but the ETT and its cuff pressure may also have a significant role internally [10]. A cadaver study by Kirskovich et al. [17] demonstrated that simple retraction during anterior cervical spine surgery can displace the larynx against the shaft of the ETT which can impinge a part of the RLN. Kako et al. [11] showed in pediatric patients that flexing and rotating the cervical spine alone could significantly increase the intracuff pressure of the ETT. It is difficult for us to confirm or comment on these factors further as our study did not investigate into the effects of the ETT cuff pressure, nor had the numbers enough to guide us to any meaningful interpretation.

Although we are well aware of the ideal positioning of the patient in beach-chair with the cervical spine in the most neutral position as achievable, and with the head itself being fixed firmly to the head rest for stability and safety, it is not always feasible to assess the neck's temporary position under the drapes while tractioning the arm temporarily during certain parts of the operation. Even these temporary maneuvers or slight malpositioning of the neck can increase the risk of injuring the nerve. Hyperextension of the neck was also shown to increase the risk of intraoperative injury in one study [12]. It is also a possibility that the strap or the reinforcement bandage over the chin and jaws could slip down or be mis-placed to strangulate the upper anterior neck in which the nerve could be vulnerable. Therefore, the surgeon needs to be fully aware of these possibilities when taking time to set up the patient in beach-chair position to avoid these complications.

The average duration of total anesthetic time for these patients was more than 2 hours which is more than the anesthetists' and the surgeon's average time for a standard shoulder arthroscopic or arthroplasty procedure. Longer operative duration can be a risk factor for the nerve injury as per previous study [24]. According to Clark et al. [27], a 'high-volume' shoulder arthroplasty surgeon being defined as having done more than 30 arthroplasties per year, has shorter operative duration in average of 105.9 minutes versus 128.3 minutes. Another study has found those arthroplasties performed under 90 minutes had fewer complications than those done with duration of more than 120 minutes [28], classifying the operative duration of more than 120 minutes as longer than standard. Agarwalla et al. [29], also reviewed 27524 cases of arthroscopic rotator cuff repairs, and found the average operative time was $86.9 \pm 37.4$ minutes. The surgeon for all of our patients is considered as an experienced, highvolume surgeon, indicating that these cases were taking longer than average, possibly due to difficult encounters, that may have predisposed to the nerve injury.

In our study, only one of the 8 patients had a lordotic alignment in the lateral cervical radiograph, and the rest had 'non-lordotic' shapes i.e. more kyphotic. An aforementioned study [11] states flexion and rotation of the cervical spine can increase the cuff pressure of the ETT therefore increasing the risk of impinging the RLN, which could imply that the tendency for the neck to be in more flexed position could predispose the nerve to the injury even during minor rotational manipulations during patient's positioning. According to Daffin et al. [20], observing their 150 asymptomatic patients' cervical spine curvatures, lordotic type's prevalence was $34 \%$ and the rest was 'non-lordotic', thus in comparison the lordotic type curvature was indeed under-represented in our affected patients. A study [21] described the average lordosis angle of 400 cervical spine radiographs as $34^{\circ}$, which was about 3 times as much as the average angle seen in our affected patients. Although the relative mobility of the cervical spines could not be assessed or obtained retrospectively, the patients' more kyphotic cervical curvatures may have been the result of years of the degenerative process, which may also imply their relative lack of mobility along with the surrounding structures including the larynx and the RLN-this may therefore increase the risk of injury with any excessive motion or when the necks are being set-up outside their usual resting positions. However, our number of the affected patients was too small to conclude with any certain link between the curvature of cervical spine and the potential risk of the nerve injury, and there had not been any other studies to investigate this link neither. Therefore, the correlation between curvature of cervical spine and the risk of vocal cord injury needs further investigation with a larger number of patient cohort.

\section{Limitations}

The small number of affected patients could not yield any meaningful statistical significance but this was inevitable given that the incidence of the RLN palsy from beach-chair position is thought to be very rare, supported by the limited reports of this complication in our current literature. For the same reason, we did not have a control group as the discrepancy between the numbers of unaffected and affected patients was massive in our cohort. This study was also retrospective which may mean that there is a potential for the loss of detailed documentation and overlooked information especially around the intricacies of airway management and intubation from the anesthesiologists' perspective, which could have a significant role in the nerve injuries as seen in the literature. This study did not confirm or quantify how much of less-than-ideal head/neck position

Page 6/12 
was involved during beach-chair positioning with the injured cases- not only this is difficult to review retrospectively, but the maximum amount of mal-positioning required to strain the larynx, thus increasing the risk of the vocal cord palsy, cannot be ascertained without further anatomical study. Therefore, a further cadaveric study is warranted to clarify this part of the investigation.

\section{Conclusions}

The incidence of vocal cord injury with beach-chair positioning at our institution was low at $0.08 \%$. The possible risk factors include long duration of the procedure and 'non-lordotic' cervical spine, as demonstrated by the trend in our study. Although rare, vocal cord injury has varying duration of recovery time, in the worst-case scenario being permanent, therefore it needs to be avoided by taking utmost care during positioning of the patient in beach-chair.

\section{Abbreviations}

ARA: absolute rotation angle

RLN: recurrent laryngeal nerve

ETT: endotracheal tube

BMI: body mass index

C: cervical

\section{Declarations}

\section{Ethics approval and consent to participate}

This study went through appropriate procedures and was approved by our institutional review board (Kyung Hee University Hospital, KHUH 2020-05058). This study was retrospective in nature, and final approval of informed consent exemption by the institutional review board (Kyung Hee University Hospital, KHUH 2020-05-058) was obtained.

\section{Consent for publication}

Not applicable

\section{Availability of data and materials}

The datasets used and/or analysed during the current study are available from the corresponding author on reasonable request

\section{Competing interests}

The authors declare that they have no competing interests

\section{Funding}

This research received no specific grant from any funding agency in the public, commercial, or not-for-profit sectors

\section{Authors' contributions}

SMY wrote draft and was a major contributor in writing the manuscript. HJK and HWL analysed and interpreted the patient data. SHC and SCM edited draft. YGR did conceptualization of the study. SMR finalized manuscript All authors read and approved the final manuscript.

\section{Acknowledgments}

We would like to thank the theatre staff at the institution for their contribution in providing photographs of the patient/table set-up that were presented in this study.

\section{References}

1. Gelber PE, Reina F, Caceres E, Monllau JC: A comparison of risk between the lateral decubitus and the beach-chair position when establishing an anteroinferior shoulder portal: a cadaveric study. Arthroscopy : the journal of arthroscopic \& related surgery : official publication of the Arthroscopy Association of North America and the International Arthroscopy Association 2007, 23(5):522-528. 
2. Higgins JD, Frank RM, Hamamoto JT, Provencher MT, Romeo AA, Verma NN: Shoulder Arthroscopy in the Beach Chair Position. Arthroscopy techniques 2017, 6(4):e1153-e1158.

3. Skyhar MJ, Altchek DW, Warren RF, Wickiewicz TL, O'Brien SJ: Shoulder arthroscopy with the patient in the beach-chair position. Arthroscopy : the journal of arthroscopic \& related surgery : official publication of the Arthroscopy Association of North America and the International Arthroscopy Association 1988, 4(4):256-259.

4. Joshi M, Cheng R, Kamath H, Yarmush J: Great auricular neuropraxia with beach chair position. Local and regional anesthesia 2017, $10: 75-77$.

5. Kim JY, Rhee YG: Ocular surface injury after shoulder surgery in the beach-chair position. International orthopaedics 2018, 42(12):2891-2895.

6. Porter JM, Pidgeon C, Cunningham AJ: The sitting position in neurosurgery: a critical appraisal. British journal of anaesthesia 1999, 82(1):117128.

7. Boisseau N, Rabarijaona H, Grimaud D, Raucoules-Aime M: Tapia's syndrome following shoulder surgery. British journal of anaesthesia 2002, 88(6):869-870.

8. Cogan A, Boyer P, Soubeyrand M, Hamida FB, Vannier JL, Massin P: Cranial nerves neuropraxia after shoulder arthroscopy in beach chair position. Orthopaedics \& traumatology, surgery \& research : OTSR 2011, 97(3):345-348.

9. Rhee YG, Cho NS: Isolated unilateral hypoglossal nerve palsy after shoulder surgery in beach-chair position. Journal of shoulder and elbow surgery 2008, 17(4):e28-30.

10. Brimacombe J, Keller C, Giampalmo M, Sparr HJ, Berry A: Direct measurement of mucosal pressures exerted by cuff and non-cuff portions of tracheal tubes with different cuff volumes and head and neck positions. British journal of anaesthesia 1999, 82(5):708-711.

11. Kako H, Krishna SG, Ramesh AS, Merz MN, Elmaraghy C, Grischkan J, Jatana KR, Ruda J, Tobias JD: The relationship between head and neck position and endotracheal tube intracuff pressure in the pediatric population. Paediatric anaesthesia 2014, 24(3):316-321.

12. Pariente L, Camarena P, Koo M, Sabate A, Armengol J: [Hypoglossal nerve neuropraxia after shoulder hemiarthroplasty]. Revista espanola de anestesiologia y reanimacion 2014, 61(5):277-280.

13. Myssiorek D: Recurrent laryngeal nerve paralysis: anatomy and etiology. Otolaryngologic clinics of North America 2004, 37(1):25-44, v.

14. Fundakowski CE, Hales NW, Agrawal N, Barczynski M, Camacho PM, Hartl DM, Kandil E, Liddy WE, McKenzie TJ, Morris JC et al: Surgical management of the recurrent laryngeal nerve in thyroidectomy: American Head and Neck Society Consensus Statement. Head \& neck 2018 , 40(4):663-675.

15. Hayward NJ, Grodski S, Yeung M, Johnson WR, Serpell J: Recurrent laryngeal nerve injury in thyroid surgery: a review. ANZ journal of surgery 2013, 83(1-2):15-21.

16. Serpell JW, Lee JC, Chiu WK, Edwards G: Stressing the recurrent laryngeal nerve during thyroidectomy. ANZ journal of surgery 2015, 85(12):962965.

17. Kriskovich MD, Apfelbaum RI, Haller JR: Vocal fold paralysis after anterior cervical spine surgery: incidence, mechanism, and prevention of injury. The Laryngoscope 2000, 110(9):1467-1473.

18. Lee SJ, Ryu CH, Kwon KH, Kim NW, Jeong HJ: Unilateral hypoglossal nerve palsy after endotracheal intubation for general anesthesia in a difficult airway patient -A case report. Anesthesia and Pain Medicine 2016, 11(2):220-223.

19. Tan TP, Govindarajulu AP, Massicotte EM, Venkatraghavan L: Vocal cord palsy after anterior cervical spine surgery: a qualitative systematic review. The spine journal : official journal of the North American Spine Society 2014, 14(7):1332-1342.

20. Daffin L, Stuelcken MC, Sayers MGL: The efficacy of sagittal cervical spine subtyping: Investigating radiological classification methods within 150 asymptomatic participants. Journal of craniovertebral junction \& spine 2017, 8(3):231-238.

21. Harrison DD, Janik TJ, Troyanovich SJ, Holland B: Comparisons of lordotic cervical spine curvatures to a theoretical ideal model of the static sagittal cervical spine. Spine 1996, 21(6):667-675.

22. Mullins RC, Drez D, Jr., Cooper J: Hypoglossal nerve palsy after arthroscopy of the shoulder and open operation with the patient in the beachchair position. A case report. The Journal of bone and joint surgery American volume 1992, 74(1):137-139.

23. Sim YH, Choi JH, Kim MK: Arytenoid cartilage dislocation after reversed total shoulder replacement surgery in the beach chair position: a case report. Korean journal of anesthesiology 2016, 69(4):382-385.

24. Kikura M, Suzuki K, Itagaki T, Takada T, Sato S: Age and comorbidity as risk factors for vocal cord paralysis associated with tracheal intubation British journal of anaesthesia 2007, 98(4):524-530.

25. Park HS, Kim HJ, Ro YJ, Yang HS, Koh WU: Delayed bilateral vocal cord paresis after a continuous interscalene brachial plexus block and endotracheal intubation: A lesson why we should use low concentrated local anesthetics for continuous blocks. Medicine 2017, 96(15):e6598.

26. Sasou S, Nakamura S, Kurihara H: Suspensory ligament of Berry: its relationship to recurrent laryngeal nerve and anatomic examination of 24 autopsies. Head \& neck 1998, 20(8):695-698.

27. Clark JC, Simon P, Clark RE, Christmas KN, Allert JW, Streit JJ, Mighell MA, Hess A, Stone J, Frankle MA: The influence of patient- and surgeonspecific factors on operative duration and early postoperative outcomes in shoulder arthroplasty. Journal of shoulder and elbow surgery 2017 , 26(6):1011-1016. 
28. Swindell HW, Alrabaa RG, Boddapati V, Trofa DP, Jobin CM, Levine WN: Is surgical duration associated with postoperative complications in primary shoulder arthroplasty? Journal of shoulder and elbow surgery 2020, 29(4):807-813.

29. Agarwalla A, Gowd AK, Yao K, BohI DD, Amin NH, Verma NN, Forsythe B, Liu JN: A 15-Minute Incremental Increase in Operative Duration Is Associated With an Additional Risk of Complications Within 30 Days After Arthroscopic Rotator Cuff Repair. Orthopaedic journal of sports medicine 2019, 7(7):2325967119860752.

\section{Figures}

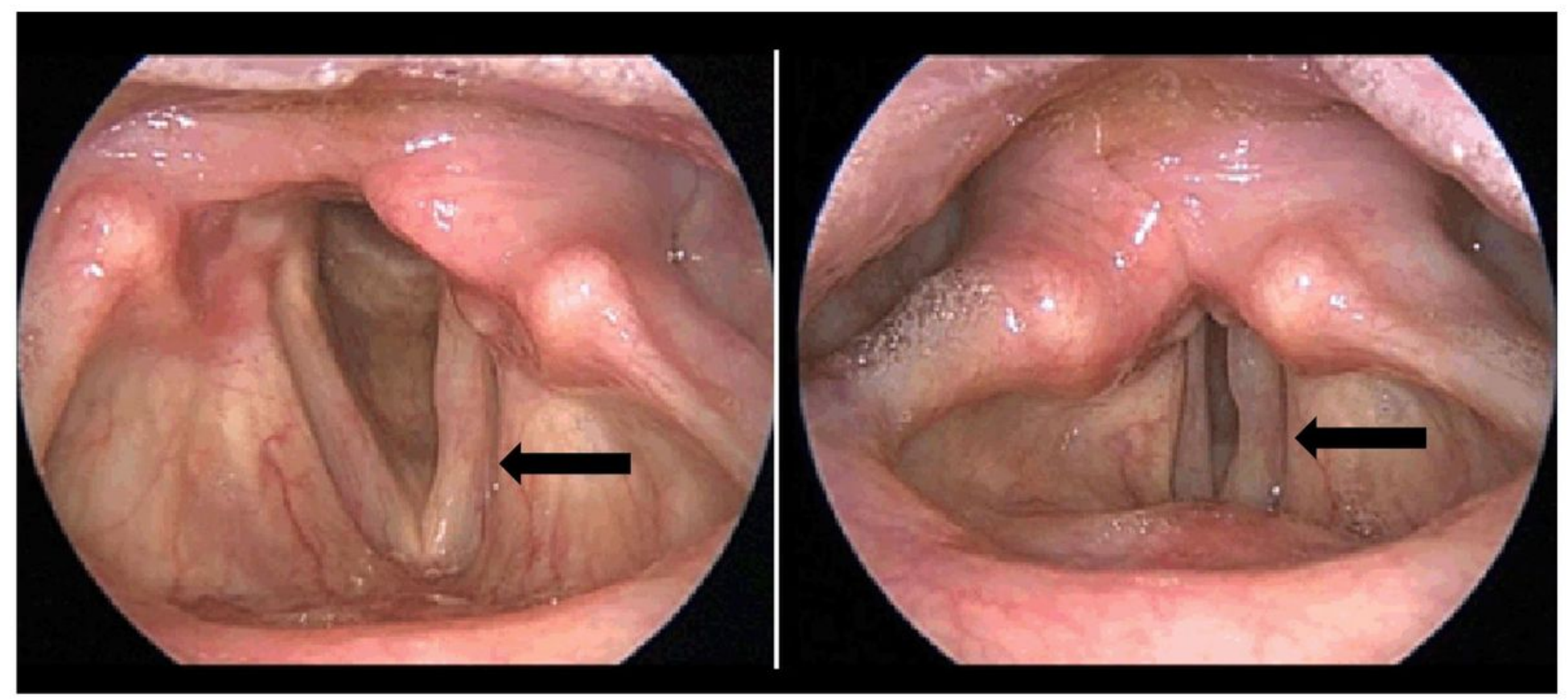

\section{Figure 1}

The laryngoscopy study captures the asymmetrical, lack of movement of the unilateral vocal cord injury (left, marked with arrow) during phonation and inhalation. 


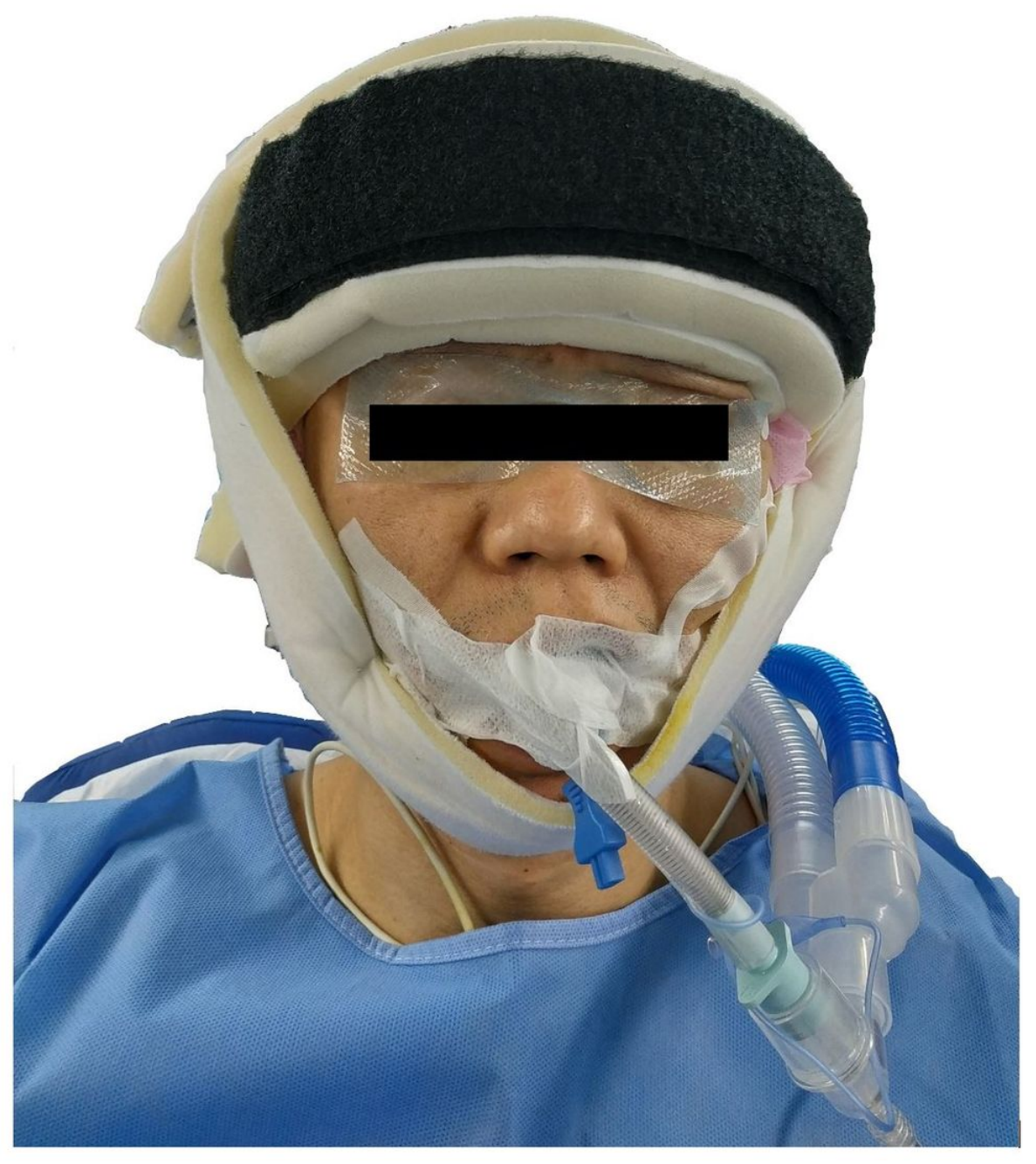

Figure 2

The patient's head and neck are secured with foamed straps across the forehead and chin, reinforced again with a Velcro strap across the forehead, which are all attached to the head holder of the beach-chair position table. 


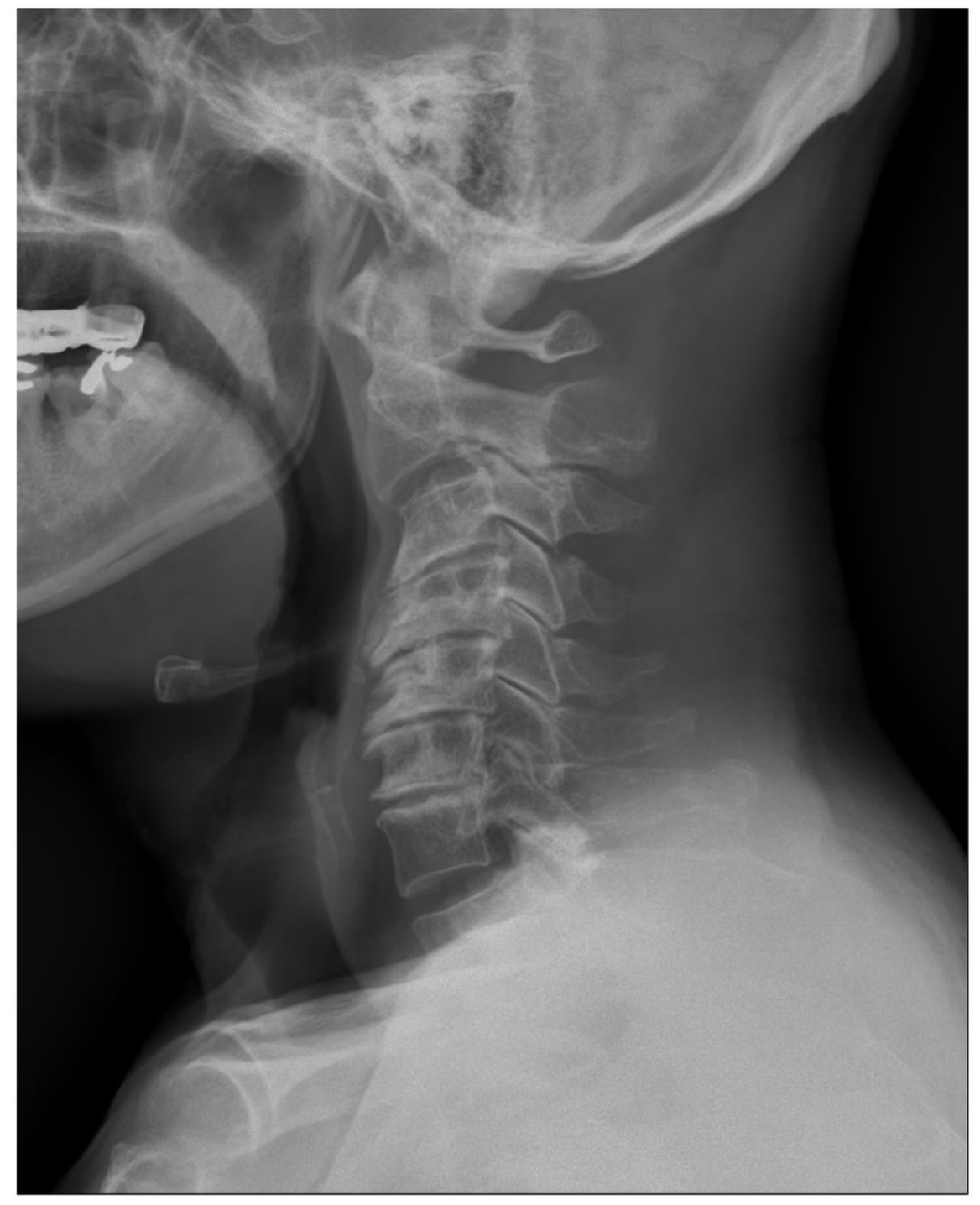

\section{Figure 3}

A 'reverse sigmoidal' cervical spine curvature was seen in one of the affected patients (case 5, Table 2). 


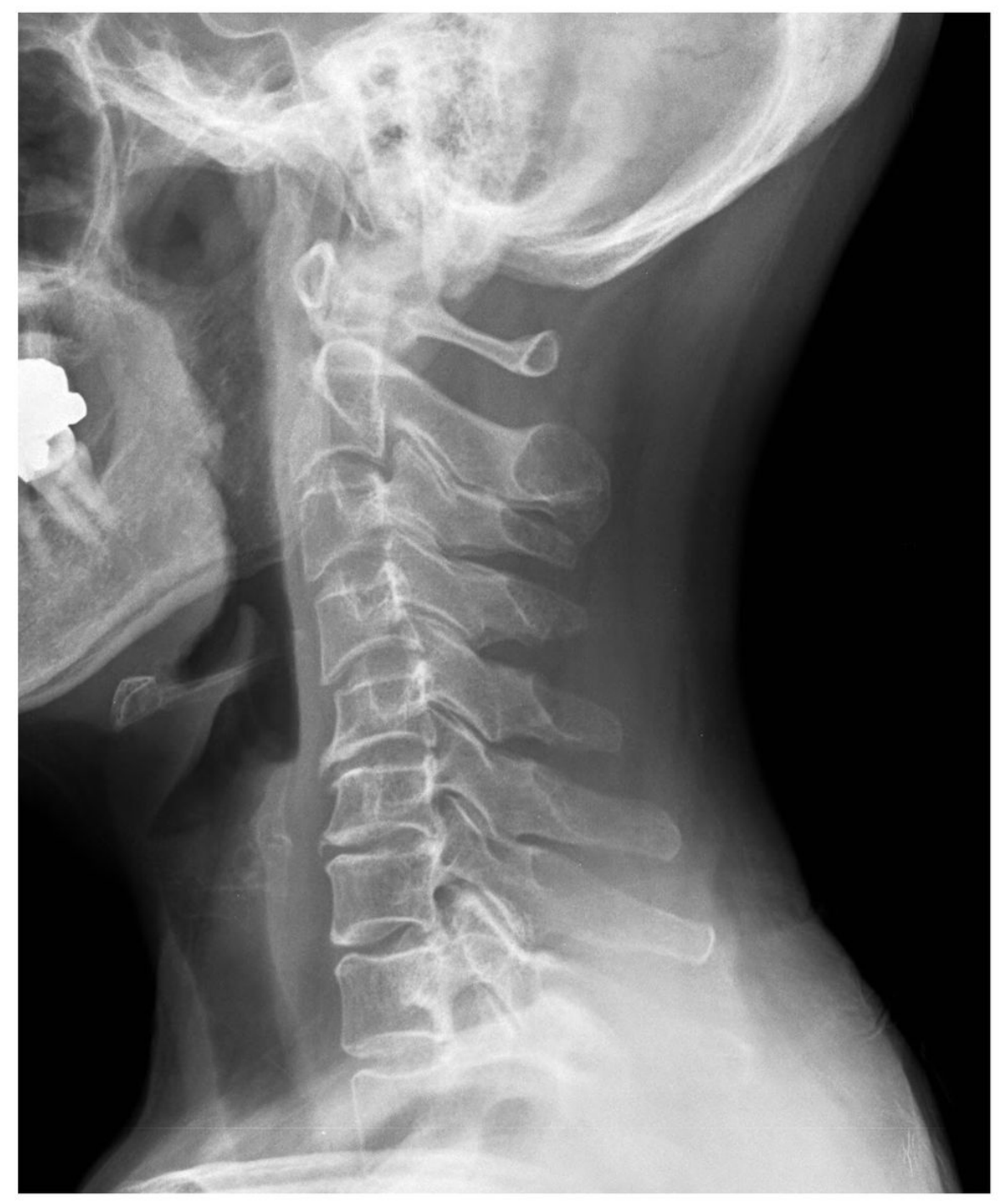

Figure 4

A 'sigmoidal' cervical spine curvature was seen in one of the affected patients (case 4, Table 2). 